\title{
Evaluation Index System of Input-Output Benefit of Distribution Network Considering Sub-Voltage Level
}

\author{
Jian $\mathrm{Tan}^{1}$, Wei Hu${ }^{1}, \mathrm{Hu} \mathrm{Li}{ }^{1}$, Xue $\mathrm{Li}^{2}$, Pengcheng Zhou ${ }^{3}$, a Yan Yang ${ }^{3}$, \\ Ming Zeng ${ }^{3}$ \\ ${ }^{1}$ State Grid Jiangsu Economic Research Institute, Jiangsu 210008, China \\ ${ }^{2}$ State Grid Nanjing Power Supply Company, Jiangsu 210008, China \\ ${ }^{3}$ school of North China Electric Power University, Beijing 102206, China \\ azhoupengcheng810@163.com
}

Keywords: Distribution network investment, Input-output benefit evaluation, Index system, Gray relational

\begin{abstract}
Under the background of the new electricity system reform, the power grid investment players have more economic requirements for Distribution Investment, and the economic and social benefits brought by Distribution Investment are paid more attention. This paper presents a model considering voltage level for evaluating the input and output efficiency of the distribution network.Firstly, the input and output evaluation system of distribution networks covering different voltage level and different categories is constructed. Secondly, through the analysis of the relevance of distribution project, a model which includes input-output benefit of distribution network is constructed based on gray relational ideal solution. On the basis of the above, the strategy of dynamic adjustment of the resolution coefficient is put forward, and the effective evaluation of the input and output efficiency of the distribution network is realized. The results of the study prove the effectiveness of the proposed method.
\end{abstract}

\section{Introduction}

A new round of power system reform has entered the implementation stage. No. nine civilization clearly put forward "orderly release of placing of electric business to social capital", and the distribution services will be gradually introduced into the market competition[1-2]. In the development of distribution network planning, in order to protect the company's stable operation, each year power grid enterprises will invest a lot of manpower, material and financial resources; In the production and operation of distribution network, through the realization of production goals, personnel performance appraisal, power grid enterprises measure the effectiveness of investment judgments, but the outputs and the resources of the distribution network are not analyzed, and the efficiency of the operation process is not reflected in the input of the distribution network side into the output, which can not be used to evaluate the resource allocation and resource utilization of the distribution network[3].

At present, some related researches have been carried out both at home and abroad. Literature [4] establishes the investment benefit evaluation and decision model of distribution network with $35 \mathrm{kV}$ and below from the aspects of overall investment benefit, investment decision and so on. In literature [5], a model of network investment evaluation under incentive supervision with multi-period optimization power flow and regulatory constraints is proposed. In literature [6], a new stochastic optimization model for distribution network investment considering the demand side response and coordinated voltage control is proposed. In literature [7-8], based on system dynamics method, the reliability index of grid investment is analyzed, and the investment optimization simulation model of distribution network is established. In literature [9], In different models of investment and financing, the economic evaluation model of grid connected distribution system and photovoltaic energy storage system is established. In addition, the literature [10] reflects the overall contribution of the investment 
to the income through the benefit index, and establishes the evaluation model with entropy weight method and comprehensive scoring method.

It can be seen that the existing results of the research still exist disadvantages in the following two aspects:

1)The current research is mainly focused on the evaluation system based on the efficiency of input index of distribution network, and the comprehensive input and output indicators have not been considered, and the overall input-output efficiency of the distribution network can not be reflected, and a partial input-output efficiency evaluation can not be carried out.

2) Most of the research is only using the deterministic method, failed to consider the impact of uncertain factors on the operation process of the distribution, and the lack of in-depth analysis (evaluation of input-output benefit of distribution network considering voltage distribution), therefore, the evaluation results often have great deviations from the actual situation, which reduces their guiding significance for planning decisions.

In view of this, based on the previous work, this paper further studies the input-output evaluation system of distribution network. First of all, according to the voltage level and different evaluation utility, a comprehensive evaluation index system of input and output benefit based on correlation analysis of distribution network project is put forward; Secondly, the evaluation model of input and output benefits of distribution network is constructed based on the method of the comprehensive weighting strategy which is combined with expert scoring and central point distance method; On this basis, in order to avoid the adverse effects of other uncertainties on the evaluation results, a dynamic adjustment strategy based on the resolution coefficient is proposed to realize the effective evaluation of the input-output efficiency of the distribution network.

\section{Efficiency Evaluation Index System Considering Sub-Voltage Level}

\subsection{Index Selection Idea}

To construct the benefit index system, we should make clear the types of input and output indexes, and analyze the correlation between them, and conclude the key indexes of input and output. Generally speaking, the input indicators mainly refer to the investment of various projects, such as to solve the equipment overload and overload investment; the output indicators mainly include the quantity, quality, efficiency, benefit of the relevant outputs, and the corresponding distribution network attributes are power supply capability, power supply quality, power grid efficiency and comprehensive benefits. In addition, the supporting indexes of distribution network should be considered as input-output, such as power grid structure, equipment level, etc. The input-output evaluation index system of the "olive shaped" distribution network is shown in figure 1. 


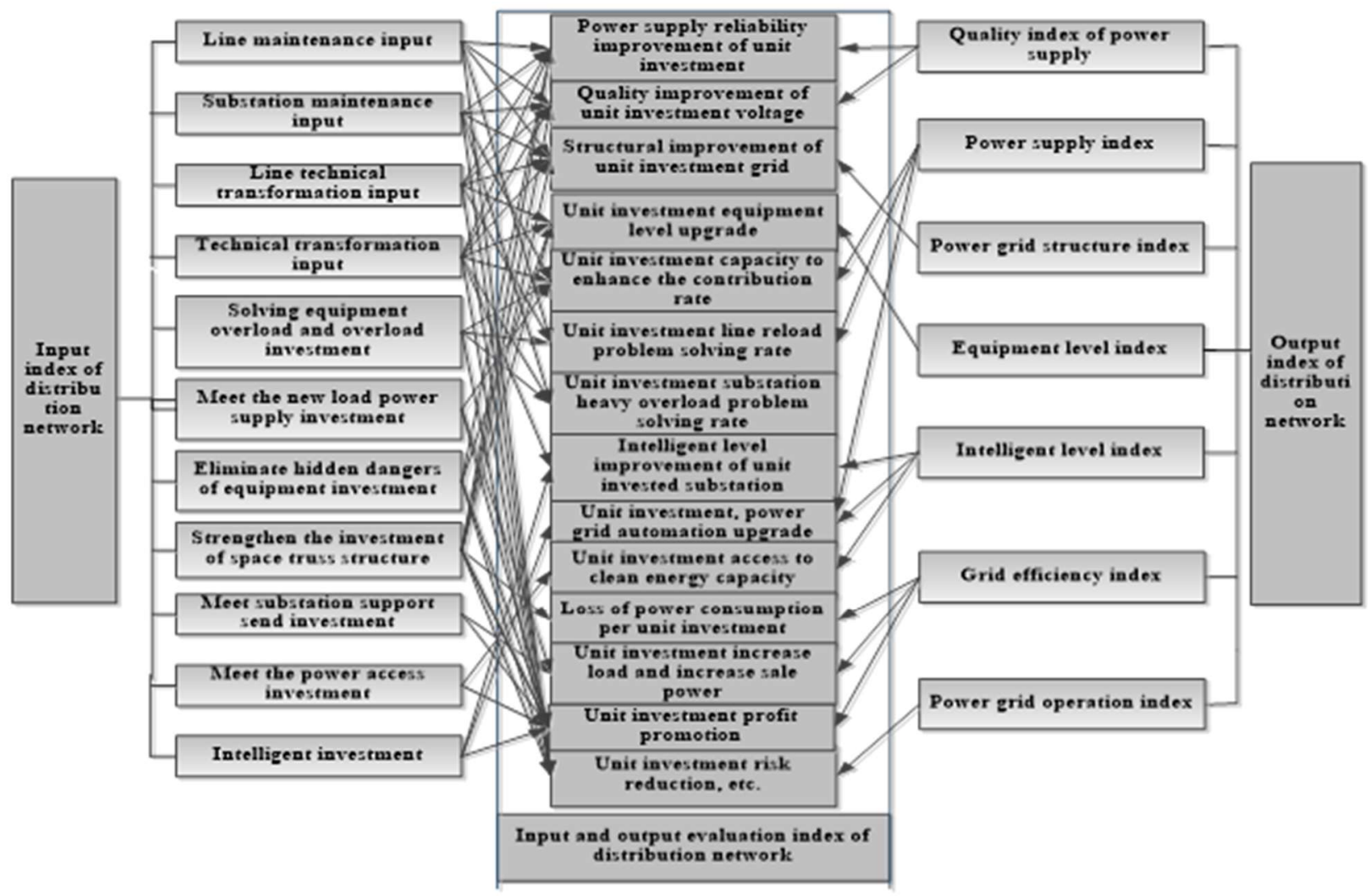

Fig. 1 Relation between input and output evaluation index system of "olive shaped" distribution network

\subsection{Index System Design}

In this paper, we consider the enterprise input resources and output data under the sub-voltage level, and the evaluation index system of input and output covering input and output indicators is constructed, which covers three aspects that contain power supply capability improvement, power grid structure upgrading and equipment level promotion. As is shown in table 1. 
Table 1 Input and output benefit evaluation index system of distribution network

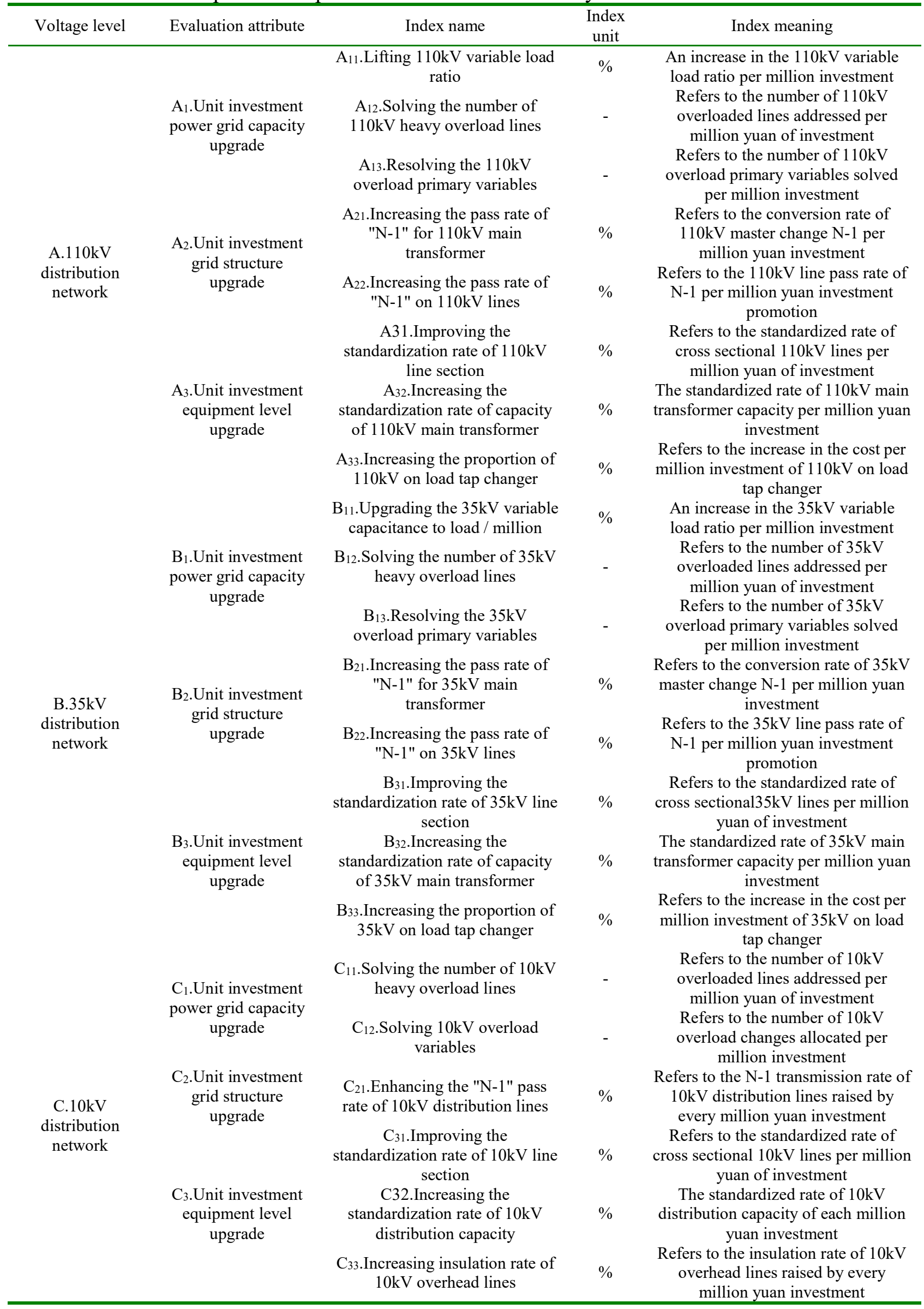




\section{Input-Output Efficiency Evaluation Based on Grey Relational Ideal Solution Combination Model}

\subsection{Ideal Solution of Grey Relation}

Technique For Order Preference By Similarity To Ideal Solution(TOPSIS) is a method proposed by C.L.Hwang and other scholars to solve the multi-objective decision-making method. The principle of TOPSIS is simple and the requirement of raw data is not high, so it has been widely used in the field of power safety accident risk operation planning, benefit analysis of distributed power deliver, Hierarchical evaluation of intelligent distribution network.

However, the traditional TOPSIS has been difficult to guarantee the effectiveness of the evaluation results. In view of this, this paper quoted by weighting method which combines the expert scoring method with the central point distance method. On this basis, using the dynamic adjustment strategy of resolving coefficients, the gray relational ideal point analysis method is constructed and applied to the actual research on input-output benefit evaluation of distribution network.

\subsection{Index Combination Weighting Setting}

For the evaluation of the input-output efficiency of distribution network, the weight assignment should be carried out according to the importance of each index in table 1-1. This paper, which uses a new combination weight based on the expert scoring-center distance, can not only reflect the importance of each index, but also reflect the value of input and output data.

The center point distance method is used as a data-driven empowerment method to reflect the extent and range of influence of relevant indicators on the target by calculating the distance between the index values and their respective center points, which can effectively deal with various types of indicators. Based on the above-mentioned method, the concrete steps of the index weighting are given as follows: 1) Construct the basic data decision matrix X. For all the elements in the matrix X, the evaluation index $\mathrm{j}$ of the index evaluation system constructed in this paper is deterministic. The decision matrix $\mathrm{Xm} \times \mathrm{n}$ is constructed for the evaluation scheme set $\mathrm{W}=\{\mathrm{w} 1, \mathrm{w} 2, \mathrm{wi}, \cdots, \mathrm{wm}\}$ and the evaluation index set $\mathrm{I}=\{\mathrm{i} 1, \mathrm{i} 2, \cdots, \mathrm{ij}, \cdots, \mathrm{in}\} ; 2)$ Due to the iHnherent differences in the dimension and type of the evaluation index $\mathrm{j}$, the basic data of the candidate program needs to be standardized. For the benefit type and cost type indexes, the corresponding standardized formulas are respectively formula (1) and formula (2).

$$
\begin{gathered}
b_{i j}=\frac{b_{i j}}{\sum_{i=1}^{m} b_{i j}} \\
b_{i j}=\frac{\frac{1}{b_{i j}}}{\left(\sum_{i=1}^{m} \frac{1}{b_{i j}}\right)}
\end{gathered}
$$

Among them, $i=1,2, \cdots, n, j=1,2, \cdots, m$, and $b i j \in[0,1]$. The index decision matrix after standardization is represented by $\mathrm{Rm} \times \mathrm{n}$. 3)Aiming at the normalized index matrix $\mathrm{Rm} \times \mathrm{n}$, according to formula (3) and (4), the central point of each evaluation index $\mathrm{j}$ and the distance named $\mathrm{Lj}$ between the index value of each selected plan to the center point are calculated respectively. Among them, $\mathrm{Lj}$ is the coefficient of variation, which indicates the degree of variability of each index value.

$$
\begin{gathered}
b_{j}=\frac{\left(\sum_{i=1}^{m} b_{i j}\right)}{m} \\
L_{j}=\frac{\sum_{i=1}^{m}\left(b_{j}-b_{i j}\right)}{m}
\end{gathered}
$$

4)The coefficient of variation $\mathrm{Lj}$ of the index value of each selected scheme is normalized, and the distance weight factor $\lambda \mathrm{j}$ of each evaluation index $\mathrm{j}$ is determined, as shown in formula (5).

$$
\lambda_{j}=\frac{L_{j}}{\left(\sum_{j=1}^{n} L_{j}\right)}
$$


5) Based on the weight value of the expert scoring and the center distance method, considering the input and output factors of each distribution network, the linear combination method is adopted to determine the combination weight value $\bar{\lambda}_{J}$ of each evaluation index $\mathrm{j}$.

$$
\bar{\lambda}_{J}=\mu \lambda_{J}+(1-\mu) \dot{\lambda}_{J}
$$

Among them, $\lambda_{J}$ represents the weight value of the index $\mathrm{j}$ determined by the expert scoring method, $\mu$ represents the proportional adjustment coefficient of the combined weight, and $\mu$ satisfies $\mu \in[0,1]$. In combination with the practical application, the value of $\mu$ in this paper is 0.5 .

\subsection{Consider the Dynamic Adjustment of Resolution Coefficients}

The important step of the evaluation index system in this paper is to quantify the difference between the input-output evaluation objective and the ideal solution of the distribution network. In any evaluation scheme $i$, the degree of difference between the evaluation index $j$ and the positive and negative ideal solutions can be expressed by the positive correlation coefficient $\gamma_{i j}^{+}$and the negative correlation coefficient $\gamma_{i j}^{-}$, respectively, and the concrete quantitative calculation formulas are shown in formula (7) and formula (8).

$$
\begin{aligned}
\gamma_{i j}^{+} & =\frac{\min _{j}^{\min }\left(\Delta F_{i j}^{+}\right)+\varepsilon_{i}^{\max \max }\left(\Delta F_{i j}^{+}\right)}{\Delta F_{i j}^{+}+\varepsilon_{i}^{\max \max }\left(\Delta F_{i j}^{+}\right)} \\
\gamma_{i j}^{-} & =\frac{\min _{j}^{\min }\left(\Delta F_{i j}^{-}\right)+\varepsilon_{i}^{\max \max _{j}}\left(\Delta F_{i j}^{-}\right)}{\Delta F_{i j}^{-}+\varepsilon_{i}^{\max \max }\left(\Delta F_{i j}^{-}\right)}
\end{aligned}
$$

Among them, $\Delta \mathrm{Fij}+$ means that the evaluation scheme $\mathrm{i}$ corresponds to the distance of positive differentiation of the index $\mathrm{j}$, and $\Delta$ Fij-stands for the distance of negative differentiation of the evaluation index $\mathrm{i}$ corresponding to the index $\mathrm{j}$. By formula (7) and (8), we can see that the size of correlation coefficient $\gamma_{i j}^{+}$is closely related to the resolution coefficient $\varepsilon j$. In this paper, the distribution correlation degree of the $i$ and the sensitivity of the model to the evaluation object will be affected by the value of the resolution coefficient $\varepsilon j$. Generally, in practical applications, the value of $\varepsilon$ is set by the decision maker and has $0 \leqslant \varepsilon \leqslant 1$, and usually the $\varepsilon$ is identical to the 0.5 [20]. However, the method is affected by subjective decision making, and the persuasiveness of the evaluation result is low. In many cases, the constant resolution coefficient will reduce the validity of the correlation coefficient.

In order to avoid the shortcomings of the above mentioned methods, the dynamic adjustment strategy is adopted aiming at the inherent characteristics of the resolution coefficient, so that the inputoutput benefit evaluation results are more objective. For the dynamic adjustment of resolution coefficient $\varepsilon$, dynamic values should be dynamically determined according to the numerical distribution of the specific data of the evaluation object. Specifically, we need to compute the average difference dynamic distance $\Delta \mathrm{Fj}$-var $=\left(\sum_{j=1}^{n} \Delta \mathrm{Fij}+\right) / \mathrm{m}$ of any evaluation index $\mathrm{j}$ in the evaluation scheme i. On this basis, the overall difference of normalized index matrix $\mathrm{Rm} \times \mathrm{n}$ is analyzed, and the boundary value factor $\mathrm{Dj}$ of matrix $\mathrm{Rm} \times \mathrm{n}$ is calculated, as shown in formula (9).

$$
D_{j}=\frac{\Delta F_{j-\mathrm{var}}}{\max _{j} \max _{j}\left(\Delta F_{i j}^{+}\right)}
$$

For any evaluation of $\mathrm{j}$, there are $\varepsilon j \in[0,1]$. Considering the influence factors of input-output benefit evaluation, the value of resolution coefficient $\varepsilon j$ is adjusted dynamically. That is, when $\mathrm{Dj}=0$, the range of $\varepsilon j$ to $0<\varepsilon j \leqslant 1$; when $\mathrm{Dj} \in(0,0.5]$, $\varepsilon \mathrm{j}$ is $\varepsilon j=4 D_{j}^{2}$; when $\mathrm{Dj}>0.5,0.8 \leqslant \varepsilon j \leqslant 1$. Based on the above dynamic adjustment strategy, it can not only enhance the resolution ability of similar data of each evaluation scheme, but also make different evaluation indexes $\mathrm{j}$ corresponding to different resolution coefficients $\varepsilon j$ and avoid the adverse effects of human factors on evaluation results. 


\subsection{Solve the Process}

Considering the sub-voltage level, the evaluation model of the input-output benefit of the distribution network based on the grey relational ideal method is as follows:

1) According to the basic data of the evaluation scheme $i$, the numerical value of the evaluation index $\mathrm{j}$ is calculated.

2) The decision matrix $X m \times n$ is established, and the value of each evaluation index is treated by dimensionless method. After the above standardization, the normalized index matrix $\mathrm{Rm} \times \mathrm{n}$ is obtained. Based on the index matrix $\mathrm{Rm} \times \mathrm{n}$, the evaluation vector $\mathrm{Wi}=\left[b_{i 1-\mathrm{var}}, b_{i 2-\mathrm{var}}, \cdots b_{i j-\mathrm{var}}, b_{i n-\mathrm{var}}\right]$ corresponding to the evaluation scheme set is calculated respectively, which $b_{i j-v a r}$ represents the median value of each program corresponding to the evaluation index $\mathrm{j}$.

3) The corresponding weight value $\bar{\lambda}_{J}$ of each input and output benefit evaluation index is calculated.

4) Determine the positive and negative ideal solutions $b_{1}^{+}$and $b_{1}^{-}$corresponding to the evaluation index $\mathrm{j}$, and construct the positive ideal scheme $\mathrm{W}+=\left[b_{1}^{+}, b_{2}^{+}, \cdots, b_{j}^{+}, \cdots b_{n}^{+}\right]$and the negative ideal scheme W- $=\left[b_{1}^{-}, b_{2}^{-}, \cdots b_{j}^{-}, \cdots b_{n}^{-}\right]$.

5) Based on the constructed positive and negative ideal schemes, the corresponding resolution coefficients $\varepsilon j$ of each evaluation index $j$ are determined according to formula (9). On this basis, according to formula (7) and formula (8), the positive correlation coefficient $\gamma_{i j}^{+}$and the negative correlation coefficient $\gamma_{i j}$ of each scheme are calculated.

6) Combine the weighted weights $\lambda_{J}$ and the positive and negative correlation coefficients into the positive ideal scheme, and calculate the grey relational grade $\mathrm{f}$ the positive ideal scheme $\beta_{i}^{+}=\sum_{j=1}^{n} \lambda_{J} \gamma_{i j}^{+}$and the grey relational grade of the negative ideal scheme $\beta_{i}^{-}=\sum_{j=1}^{n} \lambda_{J} \gamma_{i j}^{-}$.

7) Calculate the distance $d_{i}^{+}=\sqrt{\sum_{j=1}^{n}\left(w_{i}-w^{+}\right)^{2}}$ of the evaluation scheme to the ideal solution and the distance $d_{i}^{-}=\sqrt{\sum_{j=1}^{n}\left(w_{i}-w^{-}\right)^{2}}$ of the negative ideal scheme respectively. Respectively, the positive and negative ideals of the grey relational grade $\beta_{i}^{+}$and $\beta_{i}^{-}$and the positive and negative ideal scheme distances $d_{i}^{+}$and $d_{i}^{-}$are treated without a dimension.

8) Determine the closeness degree of all evaluation schemes i and ideal solutions Si. he closer the $\mathrm{Si}$ is, the stronger the combination of the evaluation scheme and the positive ideal scheme is, the better the input-output efficiency of the distribution network is; the smaller the $\mathrm{Si}$ is, the weaker the fit between the evaluation scheme and the positive ideal scheme is, the worse the input-output efficiency of the distribution network is. Among them, $s_{i}=s_{i}^{+} /\left(s_{i}^{+}+s_{i}^{-}\right)$, and $s_{i}^{+}$is the deviation distance between each evaluation scheme $\mathrm{i}$ and the positive ideal scheme, and $s_{i}^{-}$is the deviation distance between each evaluation plan $i$ and the negative ideal program. Based on the above solution process, according to the calculation value of the degree of adhesion $\mathrm{Si}$, each evaluation scheme is sorted in sequence, and the corresponding maximum is the best scheme determined by the model evaluation.

\section{Example Analysis}

\subsection{Basic Data}

In order to verify the practicability and validity of the model, in this paper, the actual distribution network of four cities in China in 2015 are selected as the research object, and the actual distribution network input data and output data of each city are comprehensively evaluated and analyzed. For the sake of comparison, this paper presents some of basic data for the investment in different provinces in 2015 as shown in Table 2. 
Table 2 Basis data of the distribution network in the cities of the province

\begin{tabular}{|c|c|c|c|c|c|c|}
\hline \multicolumn{3}{|c|}{ Distribution of network indicators (million) } & A city & B city & C city & D city \\
\hline \multirow{8}{*}{$\begin{array}{l}110 \mathrm{kV} \text { distribution } \\
\text { network investment }\end{array}$} & \multirow[b]{2}{*}{ Total investment } & New line investment & 7689 & 29163 & 8707 & 7700 \\
\hline & & $\begin{array}{l}\text { New substation } \\
\text { investment }\end{array}$ & 15382 & 43791 & 14348 & 15500 \\
\hline & \multirow{2}{*}{$\begin{array}{l}\text { Infrastructure } \\
\text { investment }\end{array}$} & $\begin{array}{l}\text { Solving equipment } \\
\text { overload and overload } \\
\text { investment }\end{array}$ & 646 & 513 & 314 & 925 \\
\hline & & $\begin{array}{l}\text { Strengthening the } \\
\text { investment of space truss } \\
\text { structure }\end{array}$ & 6321 & 8181 & 7933 & 4251 \\
\hline & \multirow{2}{*}{$\begin{array}{l}\text { Technical } \\
\text { transformation } \\
\text { input }\end{array}$} & $\begin{array}{l}\text { Line technical } \\
\text { transformation investment }\end{array}$ & 315 & 840 & 178 & 559 \\
\hline & & $\begin{array}{l}\text { Substation technical } \\
\text { transformation investment }\end{array}$ & 448 & 1145 & 120 & 906 \\
\hline & \multirow{2}{*}{ Maintenance input } & $\begin{array}{l}\text { Line maintenance } \\
\text { investment }\end{array}$ & 414 & 603 & 170 & 297 \\
\hline & & $\begin{array}{c}\text { Substation maintenance } \\
\text { investment }\end{array}$ & 418 & 370 & 213 & 533 \\
\hline \multirow{8}{*}{$\begin{array}{c}35 \mathrm{kV} \text { distribution } \\
\text { network investment }\end{array}$} & \multirow[b]{2}{*}{ Total investment } & New line investment & 1807 & 3788 & 1863 & 2726 \\
\hline & & $\begin{array}{c}\text { New substation } \\
\text { investment }\end{array}$ & 620 & 1793 & 1649 & 840 \\
\hline & \multirow{2}{*}{$\begin{array}{l}\text { Infrastructure } \\
\text { investment }\end{array}$} & $\begin{array}{l}\text { Solving equipment } \\
\text { overload and overload } \\
\text { investment }\end{array}$ & 362 & 589 & 867 & 457 \\
\hline & & $\begin{array}{l}\text { Strengthening the } \\
\text { investment of space truss } \\
\text { structure }\end{array}$ & 4822 & 3341 & 1100 & 2415 \\
\hline & \multirow{2}{*}{$\begin{array}{l}\text { Technical } \\
\text { transformation } \\
\text { input }\end{array}$} & $\begin{array}{c}\text { Line technical } \\
\text { transformation investment }\end{array}$ & 336 & 739 & 521 & 542 \\
\hline & & $\begin{array}{l}\text { Substation technical } \\
\text { transformation investment }\end{array}$ & 914 & 614 & 433 & 720 \\
\hline & \multirow{2}{*}{ Maintenance input } & $\begin{array}{l}\text { Line maintenance } \\
\text { investment }\end{array}$ & 373 & 165 & 560 & 280 \\
\hline & & $\begin{array}{l}\text { Substation maintenance } \\
\text { investment }\end{array}$ & 168 & 468 & 408 & 212 \\
\hline \multirow{6}{*}{$\begin{array}{c}10 \mathrm{kV} \text { distribution } \\
\text { network investment }\end{array}$} & \multirow{2}{*}{$\begin{array}{l}\text { Infrastructure } \\
\text { investment }\end{array}$} & $\begin{array}{l}\text { Solving equipment } \\
\text { overload and overload } \\
\text { investment }\end{array}$ & 9979 & 4418 & 3554 & 6201 \\
\hline & & $\begin{array}{l}\text { Strengthening the } \\
\text { investment of space truss } \\
\text { structure }\end{array}$ & 2360 & 2549 & 1773 & 1000 \\
\hline & \multirow{2}{*}{$\begin{array}{l}\text { Technical } \\
\text { transformation } \\
\text { input }\end{array}$} & $\begin{array}{l}\text { Line technical } \\
\text { transformation investment }\end{array}$ & 199 & 329 & 226 & 94 \\
\hline & & $\begin{array}{l}\text { Substation technical } \\
\text { transformation investment }\end{array}$ & 478 & 526 & 545 & 376 \\
\hline & \multirow{2}{*}{ Maintenance input } & $\begin{array}{l}\text { Line maintenance } \\
\text { investment }\end{array}$ & 2197 & 4780 & 3326 & 4362 \\
\hline & & $\begin{array}{l}\text { Substation maintenance } \\
\text { investment }\end{array}$ & 62 & 127 & 318 & 125 \\
\hline
\end{tabular}

\subsection{Evaluation Calculation and Result Analysis}

\subsubsection{Index Weight and Resolution Coefficient Calculation}

Based on the constructed input-output benefit evaluation index system, combined with the 2.2 2.3 section of the expert scoring-center point distance combination weighting and the distinguishing coefficient dynamic adjustment strategy, the combination weights of each evaluation index and the 
weights of the resolution coefficients are calculated for 4 cities at each voltage level, as shown in table 3 .

Table 3 Index weight and scale factor

\begin{tabular}{ccccccc}
\hline $\begin{array}{c}\text { Voltage } \\
\text { level }\end{array}$ & $\begin{array}{c}\text { Evaluation } \\
\text { attribute }\end{array}$ & $\begin{array}{c}\text { index } \\
\text { name }\end{array}$ & $\begin{array}{c}\text { Expert } \\
\text { scoring } \\
\text { weight }\end{array}$ & $\begin{array}{c}\text { Center } \\
\text { distance } \\
\text { weight }\end{array}$ & $\begin{array}{c}\text { Combination } \\
\text { weight }\end{array}$ & $\begin{array}{c}\text { Resolution } \\
\text { coefficient }\end{array}$ \\
\hline \multirow{4}{*}{$\mathrm{A}$} & $\mathrm{A}_{11}$ & 0.059 & 0.025 & 0.042 & 0.840 \\
& $\mathrm{~A}_{1}$ & $\mathrm{~A}_{12}$ & 0.048 & 0.087 & 0.068 & 1.000 \\
& & $\mathrm{~A}_{13}$ & 0.044 & 0.032 & 0.038 & 0.761 \\
& $\mathrm{~A}_{21}$ & 0.052 & 0.057 & 0.055 & 0.959 \\
& & $\mathrm{~A}_{22}$ & 0.047 & 0.020 & 0.034 & 0.877 \\
& & $\mathrm{~A}_{31}$ & 0.041 & 0.025 & 0.033 & 0.712 \\
& $\mathrm{~A}_{3}$ & $\mathrm{~A}_{32}$ & 0.039 & 0.013 & 0.026 & 0.853 \\
& & $\mathrm{~A}_{33}$ & 0.045 & 0.079 & 0.062 & 0.968 \\
& & $\mathrm{~B}_{11}$ & 0.050 & 0.062 & 0.056 & 0.667 \\
& $\mathrm{~B}_{1}$ & $\mathrm{~B}_{12}$ & 0.048 & 0.101 & 0.075 & 0.923 \\
& & $\mathrm{~B}_{13}$ & 0.044 & 0.062 & 0.053 & 0.908 \\
& $\mathrm{~B}_{2}$ & $\mathrm{~B}_{21}$ & 0.046 & 0.019 & 0.033 & 0.629 \\
& & $\mathrm{~B}_{22}$ & 0.048 & 0.021 & 0.035 & 0.883 \\
& & $\mathrm{~B}_{31}$ & 0.049 & 0.009 & 0.029 & 0.807 \\
& $\mathrm{~B}_{3}$ & $\mathrm{~B}_{32}$ & 0.040 & 0.077 & 0.059 & 0.925 \\
& & $\mathrm{~B}_{33}$ & 0.035 & 0.016 & 0.026 & 0.974 \\
& & $\mathrm{C}_{11}$ & 0.051 & 0.062 & 0.057 & 0.742 \\
& $\mathrm{C}_{1}$ & $\mathrm{C}_{12}$ & 0.045 & 0.051 & 0.048 & 0.851 \\
& $\mathrm{C}_{2}$ & $\mathrm{C}_{21}$ & 0.055 & 0.081 & 0.068 & 0.840 \\
& & $\mathrm{C}_{31}$ & 0.039 & 0.032 & 0.036 & 0.690 \\
& $\mathrm{C}_{3}$ & $\mathrm{C}_{32}$ & 0.031 & 0.049 & 0.040 & 0.852 \\
& & $\mathrm{C}_{33}$ & 0.044 & 0.020 & 0.032 & 0.948 \\
\hline
\end{tabular}

The above results show that the combination weights based on the linear weights of the principal and objective weights are more stable and effective. At the same time, because the input and output indexes of the distribution network have their own units and orders of magnitude, there may be some degree of inequality. To solve the evaluation index $j$, the input and output benefit indicators need to be treated in a dimensionless way.

\subsubsection{Input-Output Benefit Evaluation Results}

The value of the evaluation scheme $i$ corresponding to the evaluation index $j$ is calculated, as shown in table 4. Overall, the lifting evaluation attributes of the power supply capability of the unit investment grid under each voltage level are less sensitive, which shows that the investment in various areas of the city to ensure the safety and reliable operation of the power grid tends to be stable in every year; In the unit investment grid structure to enhance the evaluation attribute, under each voltage level, the City $\mathrm{C}^{\prime} \mathrm{s}$ the main transformer "N-1" pass rate and line "N-1" pass rate are significantly lower than the other three cities, which indicates that the investment in strengthening the structure of the grid is the same as that of other cities, but its output efficiency is low, and it is necessary to re-plan and design the investment scheme of the grid structure under each voltage level. 
Table 4 Results of input and output indicators of various cities

\begin{tabular}{cccccccccc}
\hline $\begin{array}{c}\text { Evaluating } \\
\text { Indicator }\end{array}$ & $\begin{array}{c}\mathrm{A} \\
\text { city }\end{array}$ & $\begin{array}{c}\mathrm{B} \\
\text { city }\end{array}$ & $\begin{array}{c}\mathrm{C} \\
\text { city }\end{array}$ & $\begin{array}{c}\mathrm{D} \\
\text { city }\end{array}$ & $\begin{array}{c}\text { Evaluating } \\
\text { indicator }\end{array}$ & $\begin{array}{c}\mathrm{A} \\
\text { city }\end{array}$ & $\begin{array}{c}\mathrm{B} \\
\text { city }\end{array}$ & $\begin{array}{c}\mathrm{C} \\
\text { city }\end{array}$ & $\begin{array}{c}\mathrm{D} \\
\text { city }\end{array}$ \\
\hline $\boldsymbol{A}_{11}$ & 2.09 & 2.67 & 2.06 & 2.01 & $\boldsymbol{B}_{21}$ & $70 \%$ & $71 \%$ & $68 \%$ & $92 \%$ \\
$\boldsymbol{A}_{12}$ & 2 & 1 & 1 & 3 & $\boldsymbol{B}_{22}$ & $94 \%$ & $94 \%$ & $82 \%$ & $85 \%$ \\
$\boldsymbol{A}_{13}$ & 2 & 8 & 1 & 2 & $\boldsymbol{B}_{31}$ & $87 \%$ & $85 \%$ & $82 \%$ & $91 \%$ \\
$\boldsymbol{A}_{21}$ & $89 \%$ & $86 \%$ & $70 \%$ & $89 \%$ & $\boldsymbol{B}_{32}$ & $82 \%$ & $89 \%$ & $82 \%$ & $84 \%$ \\
$\boldsymbol{A}_{22}$ & $92 \%$ & $97 \%$ & $95 \%$ & $97 \%$ & $\boldsymbol{B}_{33}$ & $90 \%$ & $87 \%$ & $100 \%$ & $98 \%$ \\
$\boldsymbol{A}_{31}$ & $79 \%$ & $89 \%$ & $90 \%$ & $92 \%$ & $\boldsymbol{C}_{11}$ & 72 & 41 & 49 & 35 \\
$\boldsymbol{A}_{32}$ & $89 \%$ & $94 \%$ & $90 \%$ & $88 \%$ & $\boldsymbol{C}_{12}$ & 56 & 181 & 105 & 165 \\
$\boldsymbol{A}_{33}$ & $95 \%$ & $92 \%$ & $90 \%$ & $98 \%$ & $\boldsymbol{C}_{21}$ & $44 \%$ & $41 \%$ & $37 \%$ & $48 \%$ \\
$\boldsymbol{B}_{11}$ & 1.91 & 2.31 & 2.16 & 2.32 & $\boldsymbol{C}_{31}$ & $88 \%$ & $83 \%$ & $75 \%$ & $80 \%$ \\
$\boldsymbol{B}_{12}$ & 2 & 7 & 2 & 5 & $\boldsymbol{C}_{32}$ & $82 \%$ & $81 \%$ & $77 \%$ & $98 \%$ \\
$\boldsymbol{B}_{13}$ & 2 & 10 & 5 & 2 & $\boldsymbol{C}_{33}$ & $63 \%$ & $73 \%$ & $54 \%$ & $78 \%$ \\
\hline
\end{tabular}

According to the evaluation results, the positive and negative ideal solutions were $\mathrm{W}+=[0.596$, $0.462,0.358,0.422,0.287,0.379,0.412,0.296,0.221,0.384,0.501,0.329,0.242,0.480,0.359,0.519$, $0.367,0.326,0.351,0.386,0.443,0.466]$ and $\mathrm{W}-=[0.479,0.332,0.274,0.3010 .198,0.234,0.398$, $0.275,0.202,0.302,0.469,0.278,0.185,0.359,0.331,0.473,0.343,0.248,0.295,0.365,0.358$, 0.374]. The positive and negative correlation coefficients $\gamma_{i j}^{+}$and $\gamma_{i j}^{-}$of each scheme and the grey relational grade $\beta_{i}^{+}$and $\beta_{i}^{-}$of the positive and negative ideal schemes are determined. The specific calculation results are shown in table 5 .

Table 5 The province around the city distribution network into the comprehensive evaluation results

\begin{tabular}{cllll}
\hline Calculation result & A city & B city & C city & D city \\
\hline$\beta_{i}^{+}$ & 0.731 & 0.707 & 0.621 & 0.862 \\
$\beta_{i}^{-}$ & 0.597 & 0.642 & 0.852 & 0.597 \\
$d_{i}^{+}$ & 0.828 & 0.793 & 0.973 & 0.629 \\
$d_{i}^{-}$ & 0.731 & 0.601 & 0.941 & 0.369 \\
\hline
\end{tabular}

Finally, the comprehensive evaluation results of different cities were $0.596,0.562,0.417$ and 0.663 respectively. According to the sorting of evaluation value, the degree of merit of input and output benefit evaluation scheme of distribution network is D City, A City, B city and C city. Combined with the basic data of various provinces and cities, considering analysis of numerical results, we can see that although the capital invested annually in the distribution network convergence, network output benefit is a large gap, which also verify the validity of input and output efficiency of the model in the paper. From the horizontal regional dimension, with a new round of power system reform and the regional energy development of the Internet, the efficiency of city distribution network investment by different voltage shows a rising trend, D city and A City can maintain the existing scale of investment and continue to improve the economic benefits of the city distribution network; $\mathrm{C}$ city needs to readjust the investment plan of distribution network, with emphasis on the key input indexes affecting the power grid benefit, the quality of power supply and the efficiency of power grid. Although this paper only compares the input and output economic benefits of the distribution network in 2015 , the model constructed in this paper is still applicable to thHe evaluation of input-output efficiency in the years.

\section{Summary}

The paper, which focus on the core issue of the evaluation of the input and output efficiency of the distribution network with the sub-voltage level, proposes a gray relational ideal solution model based on the comprehensive weighting method and the uncertain dynamic adjustment strategy. The main conclusions and achievements of this research include the following aspects: 
First, according to the different voltage level and the evaluation utility, through the analysis of the relationship between input and output items of the distribution network, a comprehensive evaluation index system of input and output benefits is put forward. The index system comprehensively considers the corresponding relationship between the input index and the output index, which not only reflects the input-output efficiency of the whole distribution network, but also can be applied to the input and output efficiency of a certain local power grid and a certain voltage level assessment, both holistic and targeted.

Second, the expert scoring and center distance method are combined to design and calculate the index weight, which weakens the adverse effects caused by subjective factors and objective error and improves the evaluation of scientific rationality to a certain extent. At the same time, the dynamic adjustment strategy of resolution coefficient is introduced, and the benefit evaluation model of the ideal method of grey relation is constructed, and the accurate evaluation of the input and output benefits of the distribution network is realized.

Third, the evaluation of benefits have been done due to the lateral region of the city. The numerical results show that although the capital invested in the distribution network convergence, network output benefit is a large gap, which also verify the validity of input and output efficiency of the model that is also applicable to the longitudinal time dimensions.

\section{References}

[1]. CPC Central Committee and the State Counci. Opinions on further deepening the reform of the electric power system, 2015.

[2]. J. R. Pomeda, C. Camacho. Electricity industry regulation and innovation benchmarking and knowledge management as appraisal tools. Computational Economics, 4(2003) No.2, p.334-341.

[3]. M. Ringel. Liberalising European electricity markets: opportunities and risks for a sustainable power sector. Renewable and Sustainable Energy Reviews, 7(2003) No.6, p. 485-499.

[4]. T. Amasb, M. Pollitt. Electricity market reform in the European Union: Review of progress toward liberalization and Integration. The Energy Journal, 26(2005) No.2, p.11-41.

[5]. Y. Huang, L. Söder. Assessing the impact of incentive regulation on distribution network investment considering distributed generation integration. International Journal of Electrical Power \& Energy Systems, 89(2017) No.6, p.126-135.

[6]. I.Konstantelos, S. Giannelos, G. Strbac. Strategic valuation of smart grid technology options in distribution networks. IEEE Transactions on Power Systems, 32(2017) No.5, p.1293-1303.

[7]. J. Bower, D. Bunn. Experimental analysis of the efficiency of uniform-price versus discriminatory auctions in the England and Wales electricity market. Journal of Economic Dynamics and Control, 25(2001) No.3, p.561-592.

[8]. Y. F. Liu, F. F. Wu. Impacts of network constraint on electricity market equilibrium. IEEE Trans. Power Syst, 22(2007), No.1, p.126-135.

[9]. L. Testatsion. Agent-based computational economics: growing economies from the bottom up. Artificial Life. 8(2012) No.1, p.55-82.

[10]. J. Sun, L. Testatsion. Dynamic Testing of wholesale power market designs. Computational Economics, 30(2007) No.3, p.291-327. 